\title{
EMG işareti ile FPGA tabanlı mod denetimli protez kol kontrolü
}

\author{
FPGA based mod-controlled prosthetic arm control with EMG signal
}

Uğur Can BOZ ${ }^{1, a}$, Cengiz TEPE*1,b $^{*}$ İdris SANCAKTAR ${ }^{1, c}$

${ }^{1}$ Ondokuz Mayıs Üniversitesi, Mühendislik Fakültesi, Elektrik Elektronik Mühendisliği Bölümü, 55139, Samsun

- Geliş tarihi / Received: 17.07 .2021

• Düzeltilerek geliş tarihi / Received in revised form: 21.10 .2021

- Kabul tarihi / Accepted: 27.10.2021

\begin{abstract}
Öz
Günümüzde elektromiyogram (EMG) işaretleri kas hastalıklarının tespiti, rehabitilasyon cihazları, protezler, ortezler ve insan hayatını kolaylaştırmak gibi birçok amaç ile kullanılmaktadır. Ancak gerçek zamanlı protez kol uygulamalarında, bu sistemlerin taşınabilir yapıda olması için hem kompakt bir yapıya sahip olması hem de güç tüketimi ve süre açısından optimum çözümler sunması gerekmektedir. Bu çalışmada, 2 kanallı EMG işaretleri kullanılarak Alanda Programlanabilir Kapı Dizisi (FPGA) tabanlı, gerçek zamanlı ve mod denetimli protez kol kontrolü gerçekleştirilmiştir. Ek bir sensöre ihtiyaç duymadan iki kasın birlikte kasılması ile farklı modlar arasında geçiş sağlanmıştır. FPGA kartı içerisinde EMG işaretinin ADC dönüşümü, $2 \mathrm{~Hz}$ alçak geçiren FIR süzgeç, eşikleme ve PWM işlemleri gerçekleştirilmiştir. Ayrıca her aşamada elde edilen veriler gerçek zamanlı olarak bilgisayar üzerinden izlenmesi sağlanmıştır. Çalışmanın sonucunda gerçekleştirilen protez kol hareketlerinde $\% 98$, mod değiştirme işleminin gerçekleştirilmesinde ise $\% 99$ doğruluk elde edilmiştir.
\end{abstract}

Anahtar kelimeler: EMG, FIR süzgeç, FPGA, Mod denetimi, Protez kol

\begin{abstract}
Nowadays, Electromyogram (EMG) signals are used for many purposes such as the detection of muscle diseases, rehabilitation devices, prostheses, orthoses and facilitating human life. However, in real-time prosthetic arm applications, these systems must have a compact structure and offer optimum solutions in terms of power consumption and time in order to be portable. In this study, Field Programmable Gate Array (FPGA) based, real-time and modecontrolled prosthetic arm control was performed using 2-channel EMG signals. By contracting two muscles together without the need for an additional sensor, switching between different modes is provided. ADC conversion of EMG signal, $2 \mathrm{~Hz}$ low pass FIR filter, thresholding and PWM operations are performed in the FPGA board. In addition, the data obtained at each stage was monitored in real-time on the computer. As a result of the study, 98\% accuracy was achieved in the prosthetic arm movements and $99 \%$ in the mode change process.
\end{abstract}

Keywords: EMG, FIR filter, FPGA, Mode control, Prosthetic arm

\footnotetext{
${ }^{* b}$ Cengiz TEPE; ctepe@ omu.edu.tr, Tel: (0362) 31219 19, orcid.org/0000-0003-4065-5207,

a orcid.org/0000-0003-2460-6341 $\quad{ }^{\mathrm{c}}$ orcid.org/0000-0002-4790-0124
} 


\section{Giriş \\ 1. Introduction}

EMG işaretleri, kas kasılması sırasında üretilen fizyolojik işaretlerdir (Boschmann vd., 2015; Sudharsan vd., 2020). Bu işaretler, kasların üzerindeki cilt yüzeyinden elektrotlar yardımıyla elektrik potansiyelleri olarak okunabilirler (Boschmann vd., 2015; Thukral \& Tyagi, 2015). EMG işaretleri yaşlı ve fiziksel engelli bireylere yardım amacıyla kullanılmasının yanında, ev ve ofis gibi ortamlarda insan hareketlerini desteklemek ve kolaylaştırmak amacıyla da kullanılabilir (Thukral \& Tyagi, 2015). FPGA, yeniden yapılandırılabilir mantık blokları matrisi içeren ve ara bağlantılar yoluyla birbirine bağlanan dijital entegre devrelerdir (Chabchoub vd., 2015). FPGA paralel çalışabilmesinden ötürü, düşük saat frekanslarında ve gerçek zamanlı uygulamalarda kullanilabilmektedir (Zhang vd., 2012). Ayrica donanım tasarım dilleri (HDL) aracılığıyla birçok kez programlanabilmesi sayesinde gerçekleştirilen uygulamalarda esneklik sağlamaktadır (Zhang vd., 2012).

FPGA tabanlı EMG işaret kullanılarak yapılan birçok çalışma vardır. Bunlardan bazıları sinir iletim h1z tespiti (Sudharsan vd. 2020), işaret analizi (Borbely vd., 2014; Chabchoub vd., 2015; Sundaram vd., 2016), kasılma yoğunluğuna göre kontrol işareti üretme (De Paula Felipe De Oliveira vd., 2014), protez kol kontrolü (Siddiq Ahmed vd., 2021; Tepe vd., 2020), protez parmak kontrolü (Ayvali vd., 2021) ve protez el kavrama kuvveti kontrolü (Prakash \& Sharma, 2020; Wu vd., 2021) gibi çalışmalardır.

Literatürde FPGA kullanarak yapılan birçok protez kontrol çalışmaları vardır. Boschmann ve ark. 256 kanala kadar yüksek yoğunluklu elekromiyoragrafi işaretlerinin (HD EMG) Zynq FPGA kartı üzerinde Doğrusal Diskriminant Analizi (LDA) ve zaman etki alanı (TD) özellikleri kullanarak sınıflandırılmasını sağlamıştır (Boschmann vd., 2015). Zhang ve ark. FPGA ve mikrodenetleyici kullanarak insan hareketlerini yürüyor, duruyor ve merdiven çıkıyor olmak üzere üç grupta sınıflandırmıştır (Zhang vd., 2012). Chen vd., 2016 3 kanallı EMG verileri, yongada sistem (System on Chip\&SoC) mimarisi ve Naive Bayes sınıflandırıcısı kullanılarak elde edilen veriler ile bağımsız olarak tasarlamış kolun kontrolü sağlanmıştır. EMG işaretlerini bant geçiren süzgeç, yumuşatma ve eşikleme kullanarak robot kolu kontrol etmişlerdir (Caldwell vd., 2012).

Protez uygulamaları mümkün olduğu kadar kompakt bir yapıya ve düşük güç tüketimine sahip olmalidir (Boschmann vd., 2015; Bu vd., 2004; Wöhrle vd., 2017). Ayrica elde edilen veriler gerçek zamanlı olarak işlenebilme ve çeşitli sistemlerle iletişim halinde bulunma veya verileri kaydetme olanağı barındırmalıdır (Wöhrle vd., 2017). FPGA düşük güç tüketimi, boyut avantaj1 ve eş zamanlı çalışmasından ötürü protez kol uygulamaları için oldukça uygun bir seçimdir. Bu çalışmada FPGA geliştirme kartı üzerinde Anahtarlama Mod Yöntemi ve iki adet kas üzerinden elde edilen işaretler kullanılarak çok işlevli protez kol gerçek zamanlı kontrol edilmiştir. Elde edilen EMG işaretlerinin işlenmesi için $2 \mathrm{~Hz}$ alçak geçiren FIR süzgeç kullanılmış ve bu işaretlerin sınıflandırılmasında 4 farklı eşik değerinden yararlanılmıştır. Çalışmada tanımlanan modlar arasında geçişler elde edilen kontrol işaretleri ile harici bir sensor bilgisi kullanılmadan EMG işaretleri ile sağlanmıştır.

\section{Materyal ve metot}

\section{Material and method}

Bu çalışmada gerçekleştirilen sistemin genel yapısı Şekil 1'de gösterilmiştir. İki kanallı geri beslemeli yükselteç devresinden elde edilen işaretler FPGA ile $1 \mathrm{KHz}$ örnekleme frekansı kullanılarak örneklenmiştir. EMG işareti frekans band aralığındaki yüksek frekans bileşenlerinden kaynaklı anlık olarak EMG işaretinin genliğinde değişimler oluşmaktadır. $\mathrm{Bu}$ değişimler stabil kontrol işaretinin oluşturulmasında bir engel teşkil etmektedir. Bundan dolayı, deneme yanılma yoluyla farklı frekanslarda alçak geçiren süzgeç kullanilarak en iyi sonucu veren $2 \mathrm{~Hz}$ kesim frekansı seçilmiştir. $2 \mathrm{~Hz}$ alçak geçiren süzgeç ile kontrol işaretlerinin oluşturulması sağlanmıştır. Elde edilen kontrol işaretleri kullanılarak protez kolun 6 farklı mod seçeneği ile kontrolü sağlanmıştır. 


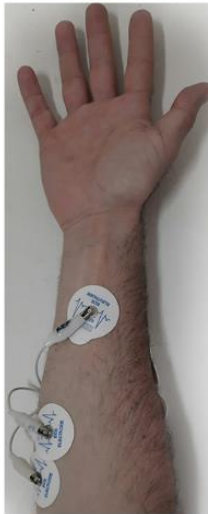

a)

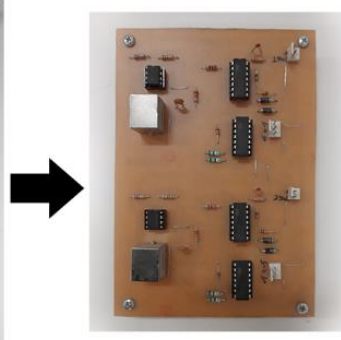

b)

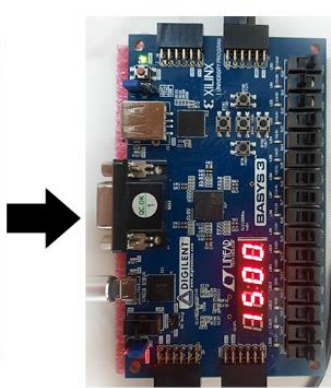

c)

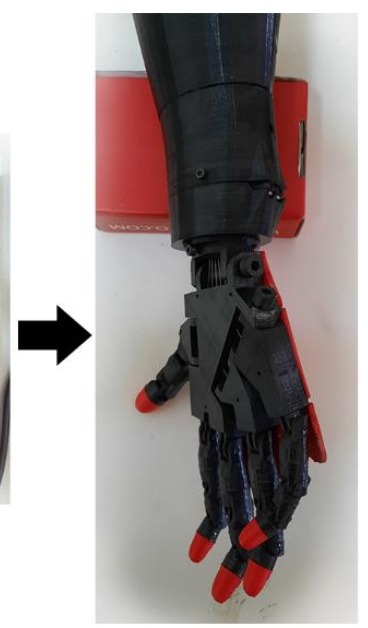

d)

Şekil 1. Sistemin genel yapısı: a) Elektrot yerleşimi, b) İki kanallı geri beslemeli yükselteç devresi, c) FPGA, d) Protez kol

Figure 1. General structure of the system: a) Electrode placement, b) Two-channel feedback amplifier circuit, c) FPGA, d) Prosthetic arm

\subsection{EMG veri alımı}

\subsection{EMG data acquisition}

Bu çalışmada kullanılan iki kanallı geri beslemeli yükselteç devresinin blok şeması Şekil 2'de verilmiștir. Bu yükselteç devresi ön yükselteç, yüksek geçiren, buffer, alçak geçiren süzgeç, tam dalga doğrultucu ve geri besleme bölümlerinden oluşmaktadır. EMG işareti 3000 kat yükselmiştir (Tepe \& Eminoğlu, 2014).

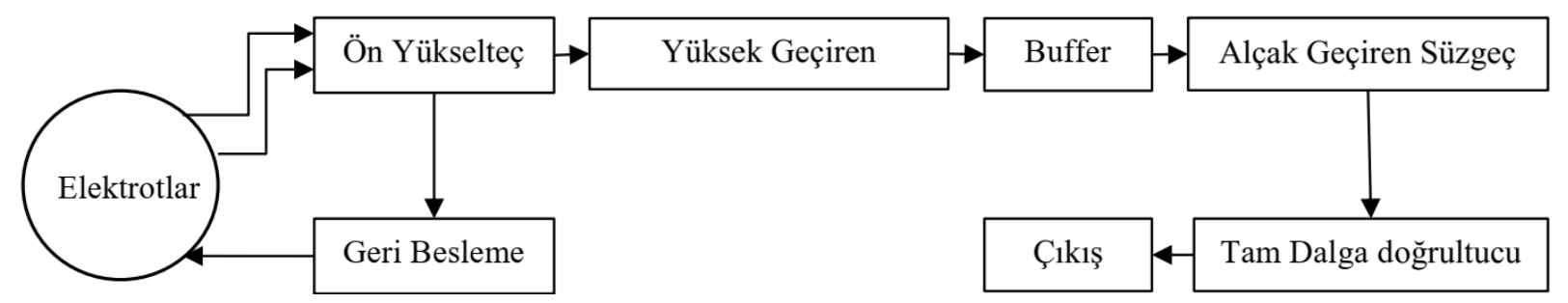

Şekil 2. Tek kanal geri beslemeli yükselteç devresi blok diyagramı

Figure 2. The block diagram of the single-channel feedback amplifier circuit

Elektrot yerleşimleri Şekil 3'de verilmiştir. Şekil 5'de gösterilen birinci kanal EMG işareti Şekil 3.a ekstensör digitorum ve ikinci kanal

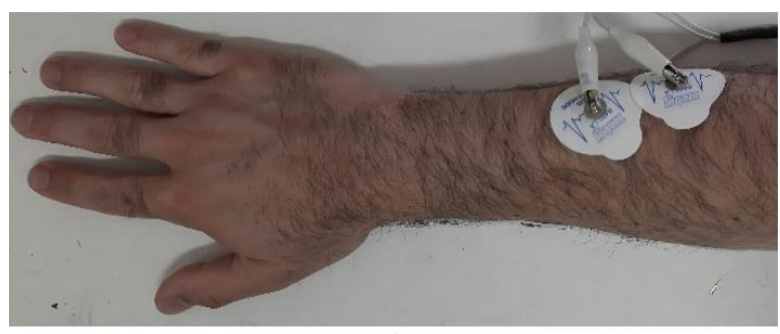

a)
EMG işareti ise Şekil 3.b'de fleksör kalpi ulnaris kasları üzerinden alınmıştır.

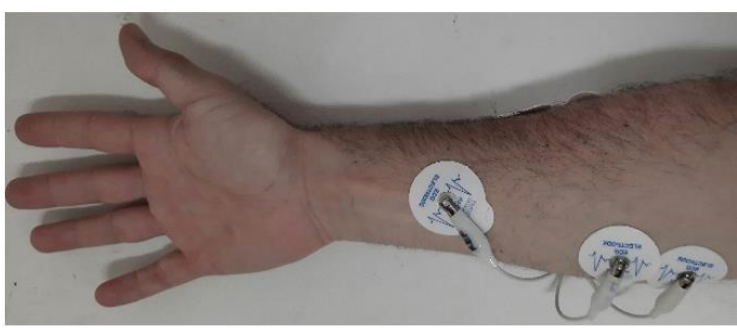

b)

Şekil 3. Elektrot yerleşimleri: a) Ekstensör digitorum, b) Fleksör kalpi ulnaris Figure 3. Electrode placements: a) Extensor digitorum, b) Flexor kalpi ulnaris

EMG ișaretleri Şekil 4'te gösterilen el hareketleri kullanılarak elde edilmiştir. El açık konumu dinlenme konumudur. Yumruk hareketi ile elde edilen işaretlerle, üçüncü ve dördüncü eşik değerleri kullanılarak mod değişikliği için kontrol işaretleri 
üretilmektedir. El dişarı ve el içeri el hareketleri ile elde edilen işaretlerle ise birinci ve ikinci eşik değerleri kullanılarak protezin

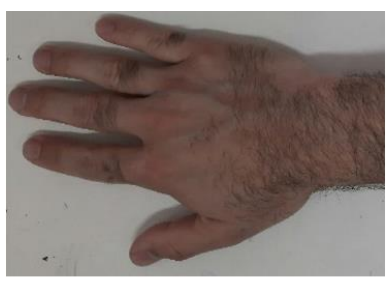

a)

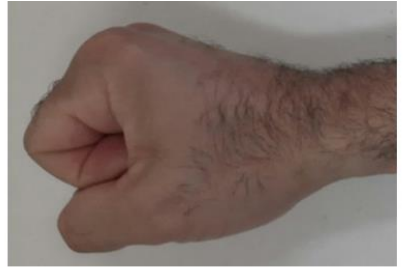

b)

bulunduğu mod içerisindeki hareketinin değiştirilmesi için kontrol işaretleri üretilmiştir.

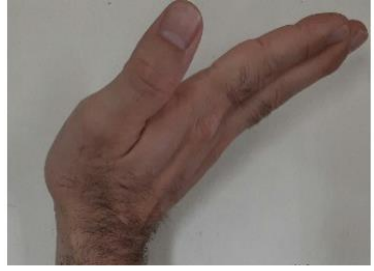

c)

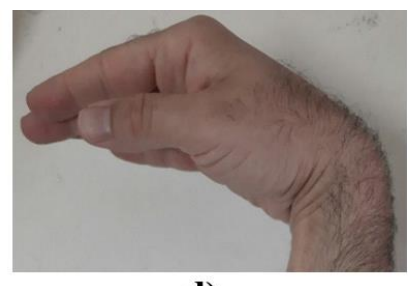

d)

Şekil 4. El hareketleri: a) El açık (dinlenme konumu), b) Yumruk Hareketi, c) El dışarı, d) El içeri Figure 4. Hand movements: a) Hand open (resting position), b) Fist Movement, c) Hand out, d) Hand in

\subsection{Eșikleme yöntemi}

\subsection{Thresholding method}

Modlar arası geçişler iki kanaldan alınan EMG verilerinin eşiklenmesi sonucu elde edilen kontrol işaretleri ile sağlanmıştır. Ayrıca FPGA kartı üzerinde harici olarak mod değişikliği de gerçekleştirilebilmektedir.

Örneklenen EMG işaretlerinden kontrol işaretlerinin elde edilmesi aşamasında, öncelikle örneklenen işaretler $2 \mathrm{~Hz}$ FIR süzgeçten geçirilir ve ardından bu işaretler üzerinde eşikleme işlemi gerçekleştirilir. Eşikleme işlemi gerçekleştirilirken her bir kanal için mod kontrol ve protez kol kontrol işaretlerini elde etmek amacıyla iki farklı eşik değeri ele alınır. Eșik değerleri EMG işaretlerinin offset seviyesi ve elin hareketleri dikkate alınarak deneme yanılma ile bulunur.
Şekil 5'te, gerçekleştirilen çalıșmada birinci ve ikinci kanaldan elde edilen EMG işaretlerinin, $2 \mathrm{~Hz}$ alçak geçiren FIR süzgeç çıkışındaki işaretleri gösterilmektedir. $\mathrm{Bu}$ ișarette birinci ve beşinci işaret el içeri hareketi, ikinci ve altıncı işaret el dışarı hareketi ve son olarak üçüncü ve dördüncü işaretler yumruk hareketi sonucunda elde edilmiştir. Bu durumlar dikkate alındığında el içeri hareketleri kullanılarak birinci eşik değeri, el dişarı hareketleri kullanılarak ikinci eşik değeri ve yumruk hareketleri kullanılarak üçüncü ve dördüncü eşik değerleri elde edilir. Ardından geliştirme kartı üzerinden deneme yanılma ile bu değerlerde iyileştirmeler gerçekleştirilir. Birinci kanal için ilk eşik değeri 1000 ve ikinci eşik değeri 760 olarak belirlenmiștir. İkinci kanal için bu değerler ilk ve ikinci eşik değeri olmak üzere sirayla 600 ve 440 olarak belirlenmiştir.
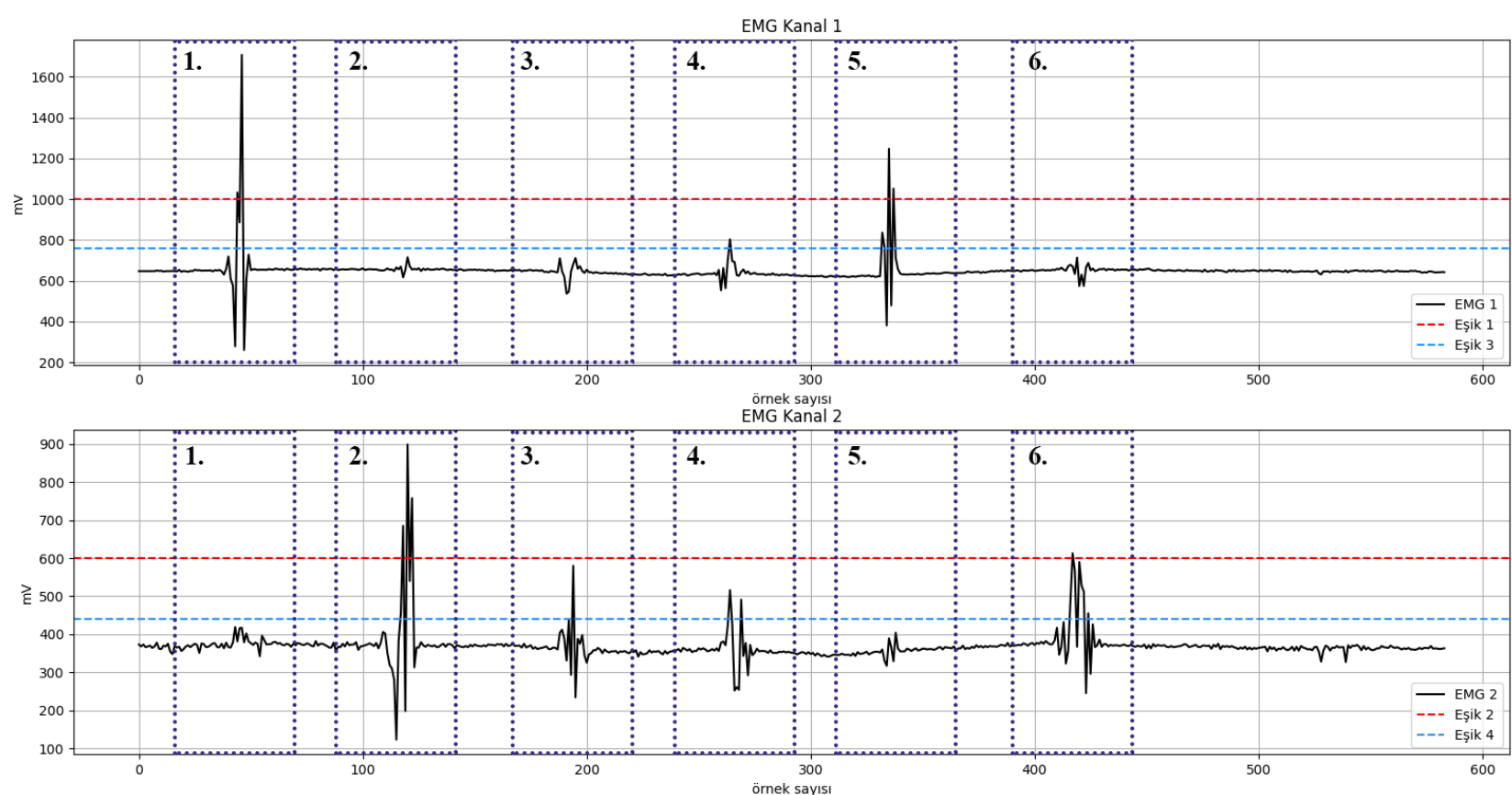

Şekil 5. İki kanallı EMG işareti

Figure 5. Two-channel EMG signal 


\subsection{FPGA kartı}

\subsection{FPGA board}

$\mathrm{Bu}$ çalışmada Şekil 1.c'de gösterilen günümüzde geniş I/O birimine, FPGA geliştirmek için temel birimlere ve Vivado ücretsiz versiyon desteğine sahip olmasından ötürü yaygın olarak kullanılan bir geliştirme kartı kullanılmıştır (Digilent Inc, 2021).

Kullanılan FPGA kartı chip üzerinde dahili ADC (Analog Digital Converter) modülüne sahiptir. Geliştirme kartının ADC referans gerilimi 1 volttur ve 12 bit çözünürlüğe sahiptir. Bu sayede $244 \mathrm{uV}$ çözünürlük sağlayabilir. Ayrıca 1 MSPS (Mega Samples Per Second) örnekleme frekansı sayesinde çalışmalar için ayrıntılı veri kümeleri sağlayabilir.

\subsection{FPGA mimari tasarımı}

\subsection{FPGA architecture design}

FPGA eş zamanlı çalışabilmesi sayesinde elimizdeki donanım koşullarının el verdiği düzeyde paralel ya da seri olarak donanım tasarımını mümkün kılmaktadır. $\mathrm{Bu}$ tasarım donanım dilleri aracılığıyla gerçekleştirilmektedir. Donanım dilleri kodlama ile bir donanım tasarımının gerçekleştirilmesini mümkün kılmaktadır. Gerçekleştirilen bu çalışmada yaygın olarak kullanılan donanım dillerinden bir tanesi olan VHDL kullanılmıştır. Çalışma da kullanılan iki ana eş zamanlı döngü Şekil 6' de gösterilmiştir. İlk döngüde yükselteç devresinden alınan EMG işaretleri $1 \mathrm{KHz}$ örnekleme frekansı ile örneklenir. $\mathrm{Bu}$ işaret $2 \mathrm{~Hz}$ alçak geçiren FIR süzgeçten geçirilerek Şekil 5'de gösterilen EMG1 ve EMG2 işaretleri elde edilir. Ardından bu işaretlerin 2 tanesi mod değişikliği ve iki tanesi protez hareketlerinin kontrolünü sağlanmak için toplamda 4 farklı eşik değeri kullanarak kontrol işaretleri elde edilir. Tüm elde edilen EMG verileri UART protokolü kullanılarak bilgisayara gönderilmektedir. İkinci eş zamanlı döngüde ise güncellenen mod değerleri ve hareket işaretleri kullanılarak sonlu durum makineleri yardımıyla protez kontrol işaretleri üretilir.

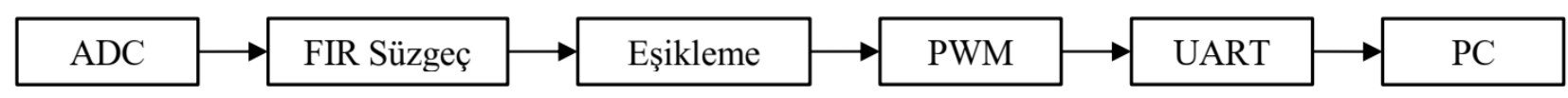

Şekil 6. EMG işaretlerinin FPGA içerisinde işlenmesi

Figure 6. The processing of the EMG signals with FPGA

Kullanım kolaylığı sağlaması amaciyla butonlar ve 7 segment üzerinde 9 farklı fonksiyona sahip menü oluşturulmuştur. Şekil 7'de gösterilen bu menü yardımıyla örnekleme sonucunda her bir kanal için elde edilen EMG genlik değerleri ve bunların süzgeç çıkışları 7 segment üzerinde gösterilebilmektedir (ikinci, üçüncü, dördüncü ve beşinci modlar). Altınc1, yedinci, sekizinci ve dokuzuncu fonksiyonlar kullanılarak kontrol işaretlerinin oluşturulması amacıyla belirlenen 4 farklı eşik değeri görüntülenebilmekte ve ayarlanabilmektedir. Birinci fonksiyon ise protezin hareketleri için yapılandırılmış 6 farklı moddan hangisinde çalışmakta olduğunu göstermekte ve ayarlanmasını sağlamaktadır.

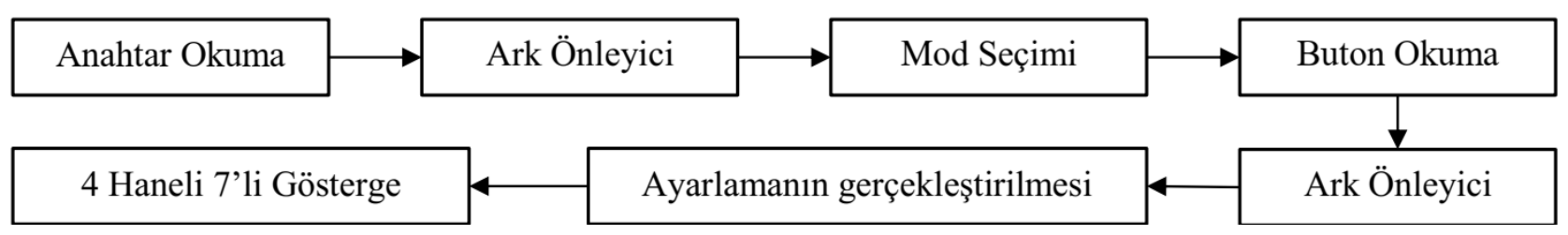

Şekil 7. Kullanıcı ekranı çalışma diyagramı

Figure 7. User screen working diagram

Gerçekleştirilen çalışma için genel akıș diyagramı Şekil 8'da verilmiştir. Akış diyagramında gösterilen EMG1 birinci kanaldan alınan ve EMG2 ise ikinci kanaldan alınan EMG işaretlerini göstermektedir. Bu işaretlerden elde edilen kontrol işaretleri Şekil 5'te gösterilmiştir. 2 kanallı EMG işaretleri kullanılarak 4 farklı kontrol işareti elde edilmiştir. Birinci durumda (el dinlenme hareketi, $\mathrm{c}=$ " 00 "), iki kontrol işaretinin 4 eşik değerinin de altında kaldığı durum gösterilmiş ve bu durumda sistem çıktısı güncellenmemiştir. İkinci durumda (el içeri hareketi, $\mathrm{c}=$ "01") ise birinci kanalın genlik değeri birinci eşik değerini geçmesi ve ikinci kanalın hiçbir eşik değerini geçmemesi 
durumu gösterilmiştir. $\mathrm{Bu}$ durumda protez hareketlerinin güncellenmesi için yön işareti $\mathrm{R}$ konumuna güncellenmiştir. Üçüncü durumda (el dişarı hareketi, $\mathrm{c}=$ "10") ikinci işaretin ikinci eşik değerini geçmesi ve ilk işaretin hiçbir eşik değerini geçmemesi durumu gösterilmiştir. Bu durumda yön işareti L olarak güncellenmiştir. Son durumda (yumruk hareketi, c = "11") iki işaretin üçüncü ve dördüncü eşik değerlerini geçmesi durumu kontrol edilmiştir. Bu durumda mod değeri bir artırılmıştır. $\mathrm{Bu}$ işlemlerle eş zamanlı olarak, güncellenen 6 farklı mod değerleri ve her bir mod içerisindeki iki farklı $(\mathrm{R}, \mathrm{L})$ kontrol işaretinden yararlanarak 250 ms'lik periyotlarda protez kol için oluşturulan PWM işaretlerinin güncellenmesi sağlanmıştır.

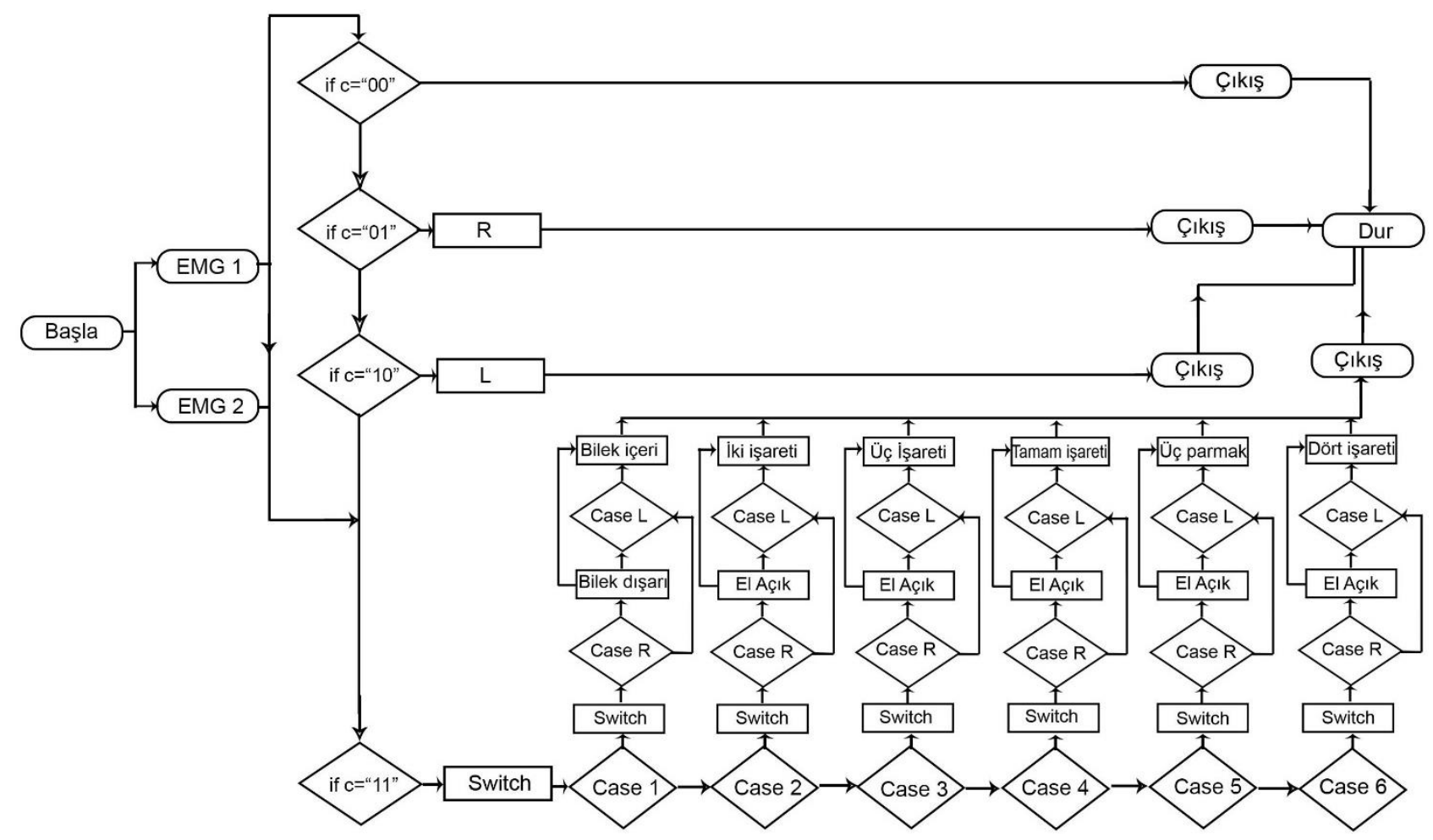

Şekil 8. FPGA akış diyagramı

Figure 8. FPGA flowchart

\subsection{FPGA ve $\mathbf{R C}$ servo motor bağlantısı} 2.5. FPGA and RC servo motor connection

Çalışmada kullanılan protez kolda parmaklar için 5 ve bilek için 1 tane olmak üzere toplamda 6 tane $\mathrm{RC}$ servo motor kullanılmıştır. Bu RC servo motorlar için kullanıldığı duruma bağlı olarak farklı açı değerleri kullanıldığından farklı PWM işaretleri üretilmiştir. RC Servo motorların beslemesi ise harici olarak güç kaynağı üzerinden sağlanmıştır.

Kullanılan geliştirme kartı üzerinde birçok giriş/çıkış pini mevcuttur. Ancak bu kartta çevresel birim ya da modül olarak hazır bir PWM çıkış1 mevcut değildir. $\mathrm{Bu}$ nedenle çıkış pinleri kullanılarak, PWM işaretleri oluşturulmuştur. Kullanılan RC servo motorların güncelleme değerlerinden dolayı oluşturulan bu işaretlerin güncelleme frekansları $4 \mathrm{~Hz}$ olarak ayarlanmıştır.
FPGA ve RC servo motor bağlantıları Şekil 9'da gösterilmiştir.

Kullanılan her bir RC servo motor için iki farklı PWM işareti oluşturulmuştur. RC servo motorların hareket açı değerleri Tablo 1'de verilmiştir. RC Servo motorların birinci açı değerleri ilk beş RC servo motor için 0 derece, altıncı RC servo motor için ise 10 derecedir. Her bir RC servo motorun ikinci açı değerleri ise birinci RC servo motordan altınc1 RC servo motora kadar sirayla olmak üzere 100, 120, 120, 100, 100, 160'tır. Protez kol ile iki işareti gerçekleştirmek için, birinci ve ikinci RC servo motorlar 0, üçüncü RC servo motor 120, dördüncü ve beşinci RC servo motorlar 100 derece olarak ayarlanmıştır. Üç işareti için birinci ve beşinci RC servo motorlar 100 derece, ikinci, üçüncü ve dördüncü RC servo 
motorlar 0 derece olarak ayarlanmıştır. El Açık (dinlenme konumu) için tüm $\mathrm{RC}$ servo motorlar 0 derece olarak ayarlanmıştır. Tamam işareti için birinci servo motor 0 derece, ikinci ve üçüncü RC servo motor 120 derece, dördüncü ve beşinci RC servo motorlar 100 derece olarak ayarlanmıştır. Üç parmak el hareketi için birinci, ikinci ve beşinci RC servo motorlar 0 derece, üçüncü RC servo motor 120 derece, dördüncü RC servo motor 100 derece olarak ayarlanmıştır. Dört işareti için beşinci servo motor 100 derece, birinci, ikinci, üçüncü ve dördüncü RC servo motorlar 0 derece olarak ayarlanmıştır. Bilek içeri hareketi için altıncı $\mathrm{RC}$ servo motor 10 derece, bilek dışarı için ise 160 derece olarak ayarlanmıştır. Farklı modlar da bilek ve parmak durumları değiştirilebilir bu sayede tüm el hareketleri hem bilek içeride hem de bilek dışarıda iken gerçekleştirilebilir.

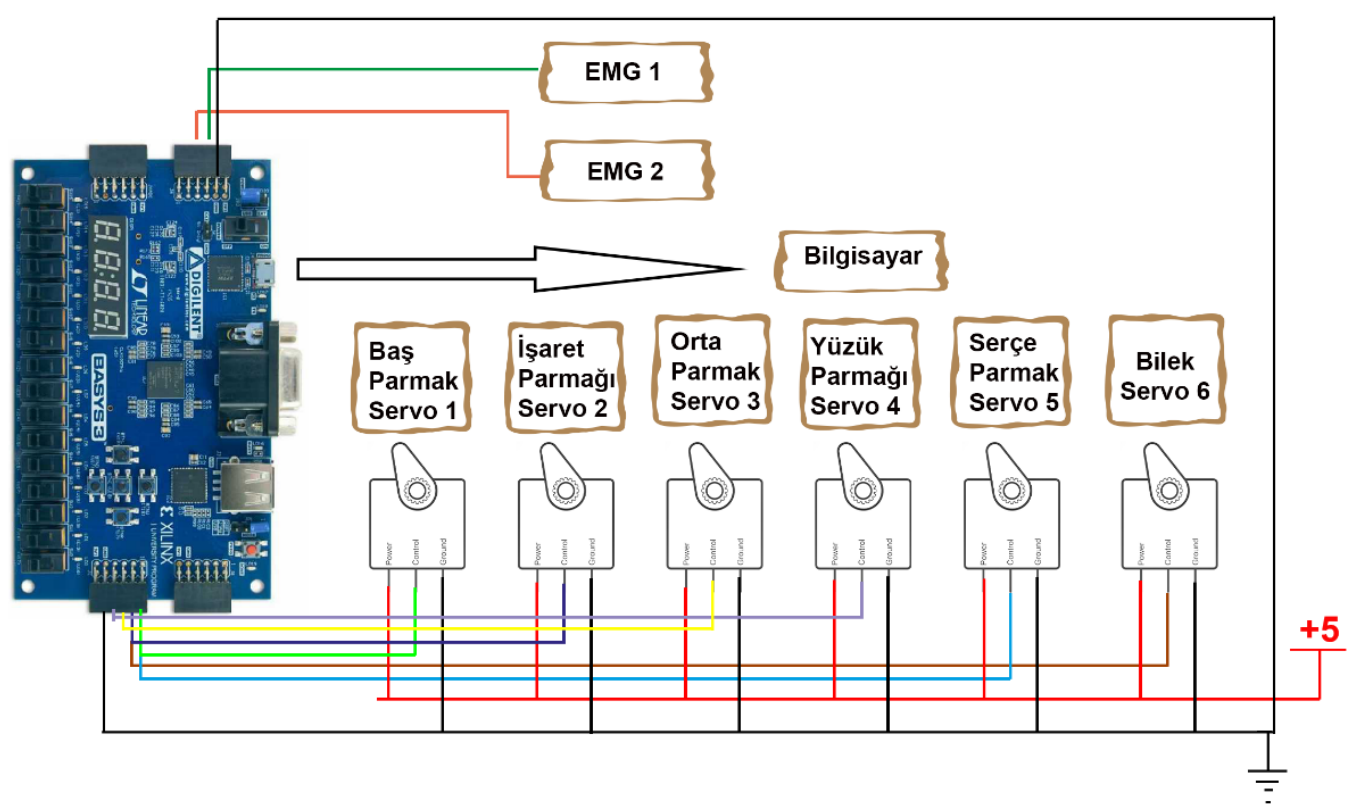

Şekil 9. RC Servo motor ve FPGA elektrik bağlantıları

Figure 9. RC Servo motor and FPGA electrical connections

Kullanılan her bir RC servo motor için iki farklı PWM işareti oluşturulmuştur. RC servo motorların hareket açı değerleri Tablo 1'de verilmiştir. RC Servo motorların birinci açı değerleri ilk beş $\mathrm{RC}$ servo motor için 0 derece, altıncı RC servo motor için ise 10 derecedir. Her bir RC servo motorun ikinci açı değerleri ise birinci RC servo motordan altıncı RC servo motora kadar sirayla olmak üzere 100, 120, 120, 100, 100, 160'tır. Protez kol ile iki işareti gerçekleştirmek için, birinci ve ikinci RC servo motorlar 0, üçüncü RC servo motor 120, dördüncü ve beşinci RC servo motorlar 100 derece olarak ayarlanmıştır. Üç işareti için birinci ve beşinci RC servo motorlar 100 derece, ikinci, üçüncü ve dördüncü RC servo motorlar 0 derece olarak ayarlanmıştır. El Açık (dinlenme konumu) için tüm RC servo motorlar 0 derece olarak ayarlanmıştır. Tamam işareti için birinci servo motor 0 derece, ikinci ve üçüncü RC servo motor 120 derece, dördüncü ve beşinci RC servo motorlar 100 derece olarak ayarlanmıştır. Üç parmak el hareketi için birinci, ikinci ve beşinci RC servo motorlar 0 derece, üçüncü RC servo motor 120 derece, dördüncü RC servo motor 100 derece olarak ayarlanmıştır. Dört işareti için beşinci servo motor 100 derece, birinci, ikinci, üçüncü ve dördüncü RC servo motorlar 0 derece olarak ayarlanmıştır. Bilek içeri hareketi için altıncı $\mathrm{RC}$ servo motor 10 derece, bilek dişarı için ise 160 derece olarak ayarlanmıştır. Farklı modlar da bilek ve parmak durumları değiştirilebilir bu sayede tüm el hareketleri hem bilek içeride hem de bilek dışarıda iken gerçekleştirilebilir.

Uygulamada 6 farklı mod denetimi gerçekleştirilmiş ve bu sayede programın farklı döngülere girmesi sağlanmıştır. Tanımlanan modlarda programın el hareketlerine karş1 üreteceği protez kol hareketleri Tablo 2'de gösterilmiştir. Burada, üst kısımda gösterilen yumruk hareketi ile modlar arası geçiş ve tablonun sol kısmında gösterilen el içeri ve el 
dışarı hareketleri ile seçili modda tanımlı iki hareket arasında geçișler kontrol edilmiștir. Mod değiştirme işlemi yumruk hareketi yapılarak değiştirilebileceği gibi butonlar ve 7 segment ile sunulan fonksiyonlar ile de değiştirilebilmektedir.

Tablo 1. RC servo motor açı aralık değerleri

Table 1. The angle range values of $R C$ servo motors

\begin{tabular}{lcccccccc}
\hline Servo Motor & $\begin{array}{c}\text { İki } \\
\text { İşareti }\left({ }^{\circ}\right)\end{array}$ & $\begin{array}{c}\text { Üç } \\
\text { Işareti } \\
\left({ }^{\circ}\right)\end{array}$ & $\begin{array}{c}\text { EI Açık } \\
\left({ }^{\circ}\right)\end{array}$ & $\begin{array}{c}\text { Tamam } \\
\text { Işsareti } \\
\left({ }^{\circ}\right)\end{array}$ & $\begin{array}{c}\text { Üç } \\
\text { Parmak } \\
\left({ }^{\circ}\right)\end{array}$ & $\begin{array}{c}\text { Dört } \\
\text { Işareti } \\
\left({ }^{\circ}\right)\end{array}$ & $\begin{array}{c}\text { Bilek } \\
\text { dişarı } \\
\left({ }^{\circ}\right)\end{array}$ & $\begin{array}{c}\text { Bilek } \\
\text { İçeri } \\
\left({ }^{\circ}\right)\end{array}$ \\
\hline Servo Motor 1 & 0 & 100 & 0 & 0 & 0 & 0 & $0 ; 100$ & $0 ; 100$ \\
Servo Motor 2 & 0 & 0 & 0 & 120 & 0 & 0 & $0 ; 120$ & $0 ; 120$ \\
Servo Motor 3 & 120 & 0 & 0 & 120 & 120 & 0 & $0 ; 120$ & $0 ; 120$ \\
Servo Motor 4 & 100 & 0 & 0 & 100 & 100 & 0 & $0 ; 100$ & $0 ; 100$ \\
Servo Motor 5 & 100 & 100 & 0 & 100 & 0 & 100 & $0 ; 100$ & $0 ; 100$ \\
Servo Motor 6 & $10 ; 160$ & $10 ; 160$ & $10 ; 160$ & $10 ; 160$ & $10 ; 160$ & $10 ; 160$ & 10 & 160 \\
\hline
\end{tabular}

Tablo 2. Protez kontrolü için gerekli el hareketleri

Table 2. The hand gestures required for controlling the prosthetic arm

\section{EI Hareketleri}

\begin{tabular}{lllllll} 
& Mod 1 & Mod 2 & Mod 3 & Mod 4 & Mod 5 & Mod 6 \\
\hline & & & & & & \\
\hline & El açık & El açık & El açık & El açık & El açık & Bilek içeri \\
\hline & $\begin{array}{l}\text { Dört } \\
\text { İşareti }\end{array}$ & $\begin{array}{l}\text { Üç } \\
\text { parmak }\end{array}$ & $\begin{array}{l}\text { Tamam } \\
\text { işareti }\end{array}$ & Üç işareti & İki işareti & Bilek dişarı \\
\hline
\end{tabular}

\section{Bulgular ve tartışma}

3. Results and discussion

Şekil 10'de iki kanallı geri beslemeli yükselteç devresinin çıkışında EMG işaretlerine ait osiloskop görüntüsü yer almaktadır. Şekilden EMG işaretlerinin başarılı bir şekilde yükseltildiği görülmektedir. Ayrıca Şekil 5'te bu işaretlerin FPGA ile örneklenmesi ve süzgeçlenmesi sonucunda bilgisayara gönderilen işaretler gösterilmektedir.
$\mathrm{Bu}$ işaretler kullanılarak protez kolun bilek içeri-dışarı hareketleri ve parmak hareketleri gerçekleştirilmiştir. Bazı protez el görüntüleri Şekil 11' de verilmiştir. Çalışma sonucunda sağlıklı bir katılımcı üzerinde gerçekleştirilen 100 denemede, el dişarı-içeri hareketleri ile elde edilen kontrol işaretlerinde $\% 98$ ve yumruk hareketi ile elde edilen mod değiştirme hareketinde $\% 99$ başarım sağlanmıştır. 


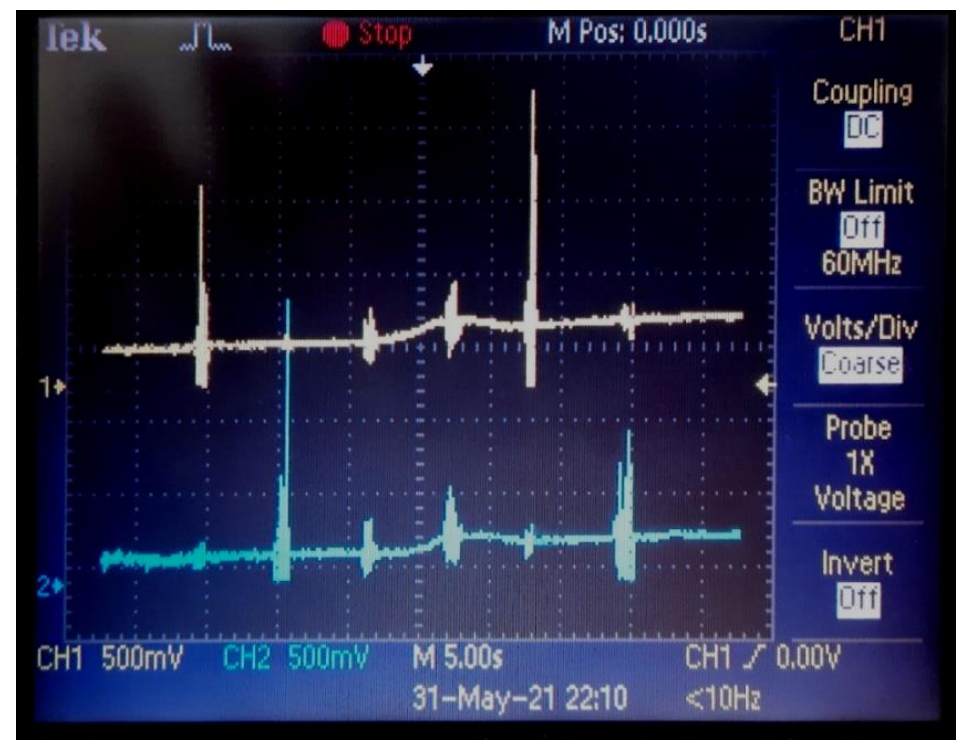

Şekil 10. İki kanallı EMG işaretinin osiloskop görüntüsü Figure 10. Oscilloscope image of two-channel EMG signal

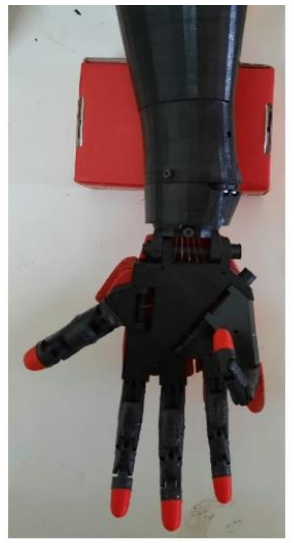

a)

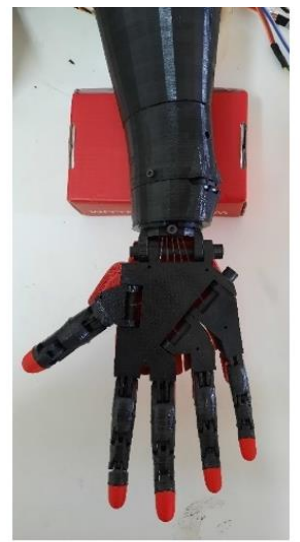

b)

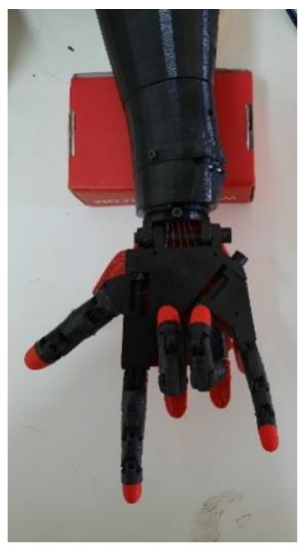

c)

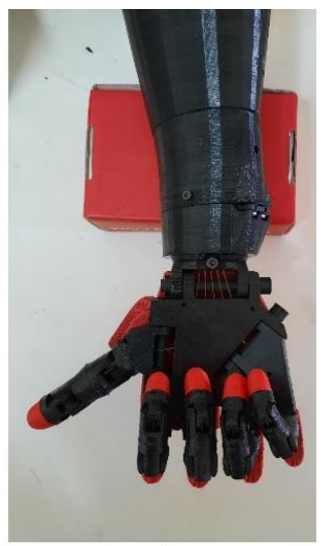

d)

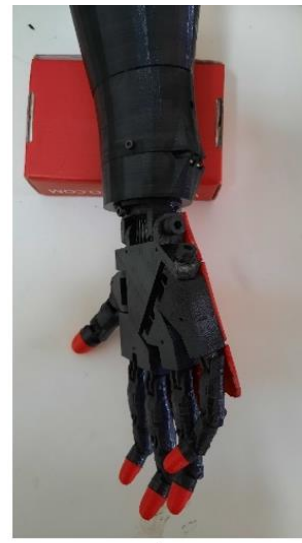

e)

Şekil 11. Protez el görüntüleri: a) Dört işareti, b) El açık, c) Üç parmak işareti, d) Tamam işareti, e) Bilek dişarı

Figure 11. Prosthetic arm images: a) Four sign, b) Hand opensign, c) Three finger sign, d) OK sign, e) Wrist out sign

Tablo 3'te gerçekleştirilen uygulamaya ait kaynak kullanımları gösterilmektedir. Burada, toplam 20800 tane birleşik mantık kapıları (LUT), 41600 tane hafiza elemanı (FF), 90 tane sayısal işaret işleme birimi (DSP), 106 tane giriş-çıkış terminali (IO) ve 32 tane tampon bellek (BUFG) bulunmaktadır.
Mevcut kaynak tüketimi göz önüne alındığında uygulamanın büyütülmesi ve geliştirilmesi için kaynak kapasitesi uygun olduğu görülmektedir. Örneğin, FPGA'de toplam 90 adet DSP bulunmasına rağmen bu çalışmada sadece 51 tanesi kullanılmıştır.

Tablo 3. FPGA Kaynak kullanımı

Table 3. FPGA resource utilization

\begin{tabular}{llll}
\hline Kaynak & Kullanılan (adet) & Toplam (adet) & Kullanılan (\%) \\
\hline LUT & 1316 & 20800 & 6.3 \\
FF & 1545 & 41600 & 3.7 \\
DSP & 51 & 90 & 56.7 \\
IO & 35 & 106 & 33.0 \\
BUFG & 4 & 32 & 12.5 \\
\hline
\end{tabular}


Tablo 4'te bu çalışmanın literatürde gerçekleştirilmiş diğer çalışmalarla güç tüketimi, gecikme ve doğruluk açısından karşılaştırılması verilmiştir.

Tablo 4. FPGA ile gerçekleştirilmiş protez kol çalışmaları

Table 4. Prosthetic arm studies performed with FPGA

\begin{tabular}{cccc}
\hline Referans (kaynak) & Güç tüketimi (W) & Gecikme (ms) & Doğruluk (\%) \\
\hline (Zhang vd., 2012) & $\mathrm{x}$ & 104 & 99.31 \\
(Chen vd., 2016) & $\mathrm{x}$ & $\mathrm{x}$ & 92 \\
Bu çalışma & 0.140 & 24 & 99 \\
\hline
\end{tabular}

Literatürde gerçekleştirilmiş benzer çalışmalar vardır (Ayvali vd., 2021; Borbely vd., 2014; De Paula Felipe De Oliveira vd., 2014; Prakash \& Sharma, 2020; Siddiq Ahmed vd., 2021; Wu vd., 2021). Ancak bu çalışmalarda güç tüketimi, kontrol işareti gecikmesi veya doğruluk açısından veri paylaşımı yapılmamıştır. Ayrıca çok modlu kontrol yapısına sahip değildirler. Naive Bayes sinıflandirıcisina dayalı protez el kontrolü gerçekleştirilmiştir. Çalışmada chip kullanımı daha düşüktür ancak sınıflandırma için 3 kanallı $\mathrm{EMG}$ işareti kullanılmıştır (Chen vd., 2016). Bunun yanında bu çalışmaya göre daha düşük bir doğruluk elde edilmiştir. Zhang ve ark. FPGA ve mikrodenetleyici kullanarak protez ayak hareketlerini üç grupta sınıflandırmıştır (Zhang vd., 2012). Gerçekleştirilen çalışmanın doğruluk oranı bu çalışma ile aynıdır ancak 4 kat daha büyük gecikme süresine sahiptir. TEPE ve ark. gerçekleştirdiği çalışmada mod değiştirme için ivmeölçer sensör kullanmışlardır (Tepe vd., 2020). Ancak bu çalışmada mod değiştirmek için insan doğasına daha uygun olan ön koldaki iki kasın aynı anda kasılması kullanılmıştır.

\section{Sonuçlar}

\section{Conclusions}

Bu çalışmada, FPGA kartı ile 2 kanallı EMG işaretleri kullanılarak yeniden yapılandırılabilir gerçek zamanlı mod denetimli protez kol uygulaması gerçekleştirilmiştir. Ayrıca modlar arası geçiş harici bir sensör kullanılmadan insan doğasına daha uygun olan EMG işareti ile gerçekleştirilmiştir. Literatürdeki diğer çalışmalara göre daha kısa sürede protez kol kontrolü sağlanmıştır. Gerçekleştirilen bu çalışmada $24 \mathrm{~ms}$ gecikme süresi ve $0.140 \mathrm{~W}$ güç tüketimi ile protez kol kontrolü $\% 98$ ve mod geçiş konrollü $\% 99$ doğruluk oranı elde edilmiştir. Bunlara ek olarak analogdan sayısala dönüştürme, sayısal süzgeç, eşikleme ve PWM işaretlerinin üretilmesi gibi birçok işlem tek chip üzerinde gerçekleştirilmiştir.

Gelecek çalışmalar da sistemin genel yapısı değiştirilmeden çok kanallı uygulamalar için genişletilebilir. Ek olarak, uygulamanın kullanıldığı alana bağlı olarak daha düşük kaynak kullanımının istendiği durumlarda DFF yerine BRAM, daha düşük kontrol gecikmesi istenen uygulamalarda ise FIR süzgeç sıralı tasarım yerine eş zamanlı olarak gerçekleştirilebilir.

\section{Yazar katkısı}

Author contribution

Tüm yazarlar makalenin her aşamasında eşit oranda katkı sağlamışlardır.

\section{Etik beyanı \\ Declaration of ethical code}

Bu makalenin yazarları, bu çalışmada kullanılan materyal ve yöntemlerin etik kurul izni ve/veya yasal-özel izin gerektirmediğini beyan etmektedir.

\section{Çıkar çatışması beyanı \\ Conflicts of interest}

Yazarlar herhangi bir çıkar çatışması olmadığını beyan eder.

\section{Kaynaklar \\ References}

Ayvali, M., Wickenkamp, I. \& Ehrmann, A. (2021). Design, construction and tests of a low-cost myoelectric thumb. Technologies, 9(3), 63. https://doi.org/10.3390/technologies9030063

Borbely, B. J., Kincses, Z., Voroshazi, Z., Nagy, Z. \& Szolgay, P. (2014). A modular test platform for real-time measurement and analysis of EMG signals for improved prosthesis control. International Workshop on Cellular Nanoscale Networks and their Applications, 1-2. https://doi.org/10.1109/CNNA.2014.6888643

Boschmann, A., Agne, A., Witschen, L., Thombansen, G., Kraus, F. \& Platzner, M. (2015). FPGAbased acceleration of high density myoelectric signal processing. 2015 International Conference on Reconfigurable Computing and 

$\begin{array}{lcc}\text { FPGAs, } & 123, & 77-89 . \\ \text { https://doi.org/10.1016/j.jpdc.2018.07.004 }\end{array}$

Bu, N., Hamamoto, T., Tsuji, T. \& Fukuda, O. (2004). FPGA implementation of a probabilistic neural network for a bioelectric human interface. The 2004 47th Midwest Symposium on Circuits and Systems, iii-29. https://doi.org/10.1109/MWSCAS.2004.135428 3

Caldwell, P., Al-Bayaty, R., Kellar, C. \& Shin, I. (2012). Biomechanics: surface electromyography prosthesis control. 5th International Conference on BioMedical Engineering and Informatics (BMEI 2012), 786-789. https://doi.org/10.1109/BMEI.2012.6512954.

Chabchoub, S., Mansouri, S. \& Salah, R. B. (2015). Biomedical monitoring system using LabVIEW FPGA. 2015 World Congress on Information Technology and Computer Applications, 1-5. https://doi.org/10.1109/WCITCA.2015.7367020

Chen, X., Ke, A., Ma, X. \& He, J. (2016). SoC-based architecture for robotic prosthetics control using surface electromyography. 8th International Conference on Intelligent Human-Machine Systems and Cybernetics, 1, 134-37. https://doi.org/10.1109/IHMSC.2016.31

De Paula Felipe De Oliveira, J., Junior, E. A. \& Roda, V. O. (2014). A reconfigurable control system using EMG. 2014 IEEE International Instrumentation and Measurement Technology Conference (I2MTC) Proceedings, 1318-1321. https://doi.org/10.1109/I2MTC.2014.6860959

Digilent Inc.: Basys 3 FPGA board reference manual power supplies. (2021, July 15). https://www.digilentinc.com

Prakash, A. \& Sharma, S. (2020). A low-cost system to control prehension force of a custom-made myoelectric hand prosthesis. Research on Biomedical Engineering, 36(3), 237-47. https://doi.org/10.1007/s42600-020-00064-w

Siddiq Ahmed, S., Almusawi, A. R. J., Yilmaz, B. \& Dogru, N. (2021). Design and multichannel electromyography system-based neural network control of a low-cost myoelectric prosthesis hand. Mechanical Sciences, 12(1), 69-83. https://doi.org/10.5194/ms-12-69-2021

Sudharsan, R. R., Deny, J., Muthukumaran, E. \& Selvi, S. C. (2020). Design, implementation, and estimation of MFCV for 4-different position of human body using FPGA. Microelectronics Journal, 105. https://doi.org/10.1016/j.mejo.2020.104890

Sundaram, K., Marichamy \& Pradeepa. (2016). FPGA based filters for EEG pre-processing. 2016 2nd International Conference on Science Technology Engineering and Management (ICONSTEM) (ss. 572-576)

https://doi.org/10.1109/ICONSTEM.2016.7560 958

Tepe, C. \& Eminoğlu, İ. (2014). Düşük maliyetli mayoelektrik denetimli protez el projesi. 16. Otomatik Kontrol Ulusal Toplantısl (ss. 657-662). Kocaeli.

Tepe, C., Erdim, M. \& Eminoğlu, I. (2020). Myo bileklik ile gerçek zamanlı protez kol kontrolü. European Journal of Science and Technology, 184-93. https://doi.org/10.31590/ejosat.779672

Thukral, R., Gulshan, M. \& Tyagi, M. P. (2015). Hardware implementation to develop prosthetic hand-a review. International Journal of Engineering Development and Research, 3(3).

Wöhrle, H., Tabie, M., Kim, S. K., Kirchner, F. \& Kirchner, E. A. (2017). A hybrid FPGA-based system for EEG- and EMG-based online movement prediction. Sensors (Switzerland) 17(7). https://doi.org/10.3390/s17071552

Wu, H., Dyson, M. \& Nazarpour, K. (2021). Arduinobased myoelectric control: towards longitudinal study of prosthesis use. Sensors (Switzerland), 21(3), 1-13. https://doi.org/10.3390/s21030763

Zhang, X., Huang, H. \& Yang, Q. (2012). Implementing an FPGA system for real-time intent recognition for prosthetic legs. Proceedings - Design Automation Conference (ss. 169-175). New York: Association for Computing Machinery. https://doi.org/10.1145/2228360.2228394 